\title{
BIOSSENSOR AMPEROMÉTRICO PARA DETECÇÃO SCREENING DE INSETICIDAS CARBAMATOS EM ÁGUAS DE ABASTECIMENTO
}

\author{
CLARA VIRGÍNIA VIEIRA CARVALHO OLIVEIRA MARQUES* \\ PAULO ROBERTO BRASIL DE OLIVEIRA MARQUES** \\ GILVANDA SILVANUNES***
}

Biossensor amperométrico, baseado em enzimas colinesterases (AChE) imobilizadas em eletrodo do tipo screen-printing, foi utilizado na investigação de teores de pesticidas carbamatos (carbofuran e carbaril) em amostras de água de abastecimento. Inicialmente, efetuou-se o estudo das constantes de inibição dos pesticidas carbaril $\left(1 \times 10^{7}\right)$ e carbofuran $\left(5 \times 10^{4}\right)$. Utilizou-se sistema com eletrodo de dois canais, composto de grafite modificada com $\mathrm{TCNQ}$ e $\mathrm{Ag} / \mathrm{AgCl}$, como eletrodos de trabalho e referência, respectivamente. Dois processos de imobilização enzimática foram estudados, visando otimização do biossensor. A metodologia de fotopolimerização com álcool polivinílico modificado com grupos estirilpiridínicos (PVA-SbQ) e a de glutaraldeido foram selecionadas para o estudo, sendo que a imobilização com PVA-SbQ apresentou melhores resultados (CV $=6,5 \%)$. Curvas analíticas foram plotadas após os ensaios de inibição com os pesticidas e os limites de detecção (LD) determinados. Carbaril apresentou curva linear (LD de $18 \mu \mathrm{g} \mathrm{L}^{-1}$ ), enquanto o carbofuran demonstrou curva com comportamento logarítmico (LD de 0,05 $\left.\mu \mathrm{g} \mathrm{L}^{-1}\right)$. Para avaliar a precisão, amostras de água de abastecimento foram fortificadas com os pesticidas estudados em três níveis de fortificação. As recuperações variaram de $93,3 \%$ a $102,7 \%$. Os biossensores a base de AChE atenderam às exigências analíticas para a direta aplicação de sensores descartáveis em amostras reais.

PALAVRAS-CHAVE: BIOSSENSORES AMPEROMÉTRICOS; CARBAMATOS; ÁGUAS DE ABASTECIMENTO; CARBARIL; CARBOFURAN.

* Doutoranda em Química, Departamento de Química, Universidade Federal de São Carlos, São Carlos, SP (e-mail: clarabrasil54@bol.com.br).

** Doutorando em Química Analítica, Instituto de Química, Universidade Estadual Paulista (UNESP), Araraquara, SP (e-mail: paulobrasil@iq.unesp.br).

*** Doutora em Química Analítica, professora do Departamento de Tecnologia Química, Universidade Federal do Maranhão (UFMA), São Luís, MA (e-mail: vandasn@ufma.br). 


\section{INTRODUÇÃO}

Os pesticidas têm sido responsáveis por grande parte dos estudos e investigações da comunidade científica. Essas pesquisas vêm sendo direcionadas para a detecção, quantificação e monitoramento desses poluentes, objetivando entender o seu comportamento e a sua interação com o meio ambiente (O'NEIL, 1993; STANLEY, 1993; BOTKLIN e KELLER, 2000). Dentre esses compostos, os carbamatos têm sido muito utilizados para o controle de pragas indesejáveis. Apesar de pouco persistentes, os carbamatos apresentam elevada toxicidade, sendo inibidores das enzimas colinesterases presentes nos organismos dos insetos e mamíferos (WHEELER; 2002; NUNES e RIBEIRO, 1999). Essas enzimas atuam no sistema nervoso, controlando impulsos e transmissões dos estímulos nervosos. Os carbamatos agem sobre o centro ativo esteárico da enzima, inibem sua ação e causam distúrbios no controle dos estímulos. Isso pode ocasionar, desde pequenas náuseas e vômitos até violentas contrações intestinais, espasmos musculares e convulsões que podem levar à morte do organismo (HASSAL, 1990; NUNES, 1996; STEVENS, 1997; SUWANSA-ARD et al., 2005).

A investigação de pesticidas depara-se com problemas analíticos complexos, ocasionados pela gama de substâncias existentes a serem determinadas em distintos produtos agrícolas, possivelmente presentes em níveis de traços. Métodos baseados em espectrofotometria e cromatografia a líquido ou a gás têm sido validados, apresentando-se muito sensíveis e sendo cada vez mais usados nesses tipos de análises (SALAU et al., 1994; BICCHI, DAMATO e BALBO, 1997; LI et al., 2004). Contudo, tais métodos exigem diversas etapas de bancada (como clean up) para eliminar interferentes, o que têm provocado baixos índices de recuperações (BARCELÓ, 1993; LEHOTAY, 1995).

Os biossensores surgiram como métodos analíticos alternativos. São arranjos que apresentam, em geral, elevadas sensibilidade e seletividade, com tempo de resposta bastante curto e mínimo tratamento da amostra (FATIBELLO FILHO e CAPELATO, 1992; MARTY, GARCIA e ROUILLON, 1995; JANATA, JOSOWICZ e DEVANEY, 1994). Na área de controle ambiental, principalmente para monitoramento de pesticidas, vários biossensores eletroquímicos a base de enzimas colinesterases (AChE) foram desenvolvidos para a detecção de resíduos de pesticidas carbamatos e organofosforados em diversas matrizes ambientais. Esses sistemas baseiam-se no princípio de inibição enzimática para determinação/quantificação desses inibidores de colinesterases (BASSI et al., 1996; CHEMNITIUS et al., 1996; SCHEPER et al., 1996; MARQUES et al., 2004). Biossensores do tipo descartáveis, também conhecidos como biossensores impressos (screen printed), têm sido estudados como instrumentos para investigações confirmatórias (alarme), buscando economia de tempo e de investimentos. São empregados para detectar amostras potencialmente positivas em análise prévia de controle do ambiente. Na segunda etapa pode-se utilizar metodologia validada e mais precisa, como a cromatografia. Contudo, poucos estudos têm efetuado a aplicação real dessas metodologias diretamente em matrizes de interesse ambiental ou populacional (SKLÁDAL, 1991; ALBAREDASIRVENT, MERKOÇI e ALAGRET, 2000; ZHANG e YANG, 2000). A configuração dos biossensores de filmes impressos é normalmente constituída por camadas da pastas especiais sobrepostas, depositadas seqüencialmente sobre determinado suporte. É considerada como técnica promissora, pois pode ser comercializada em larga escala com vantagens atrativas, como miniaturização, versatilidade, baixo custo e possibilidade de produção em massa (MARTY, GARCIA e ROUILLON, 1995). A otimização da metodologia de construção desses sensores deve buscar melhor desempenho, levando em consideração parâmetros como, a sensibilidade e a reprodutibilidade do sinal obtido. Tratando-se de sensores para o propósito de uso descartável, o sinal analítico deve fornecer baixos desvios. Estudos que buscam estabelecer e validar esses parâmetros, bem como aplicar tais sensores em amostras reais, ainda são poucos na literatura (SCHELLER e SCHMID, 1991; NUNES et al., 1998; NUNES et al., 2001).

Este trabalho objetivou a construção de biossensor amperométrico do tipo impresso, baseado em enzimas acetilcolinesterases comerciais para detecção screening de pesticidas carbamatos. Foram efetuados estudos de procedimentos de imobilização, atividade e inibição enzimática, bem como avaliação de exatidão do método de deteç̧ão. 


\section{MATERIAL E MÉTODOS}

\subsection{MATERIAL E REAGENTES}

Enzimas acetilcolinesterases (AChE), oriundas de enguia elétrica (ee) (Sigma/USA) foram escolhidas para a construção do biossensor amperométrico. Estocaram-se as enzimas sob refrigeração a -4ํㅡ. Soluções-estoque foram preparadas no próprio frasco, com adição de $1 \mathrm{~mL}$ de solução de $\mathrm{NaCl}$ $0,9 \%(\mathrm{~m} / \mathrm{v})$. Usou-se cloreto de acetiltiocolina (ATChCl, Sigma Aldrich/Alemanha) como substrato da enzima. Soluções de ATChCl foram preparadas em tampão fosfato, $\mathrm{pH} 7,5\left(\mathrm{Na}_{2} \mathrm{HPO}_{4}, \mathrm{NaH}_{2} \mathrm{PO}_{4}\right.$ contendo $\mathrm{KCl}$ 0,05 mol L-1 $)$. Soluções de ácido ditiobisnitrobenzóico (DTNB) foram preparadas em tampão fosfato. Os agentes de imobilização enzimáticos, álcool polivinílico contendo grupo estirilpiridínicos (PVA$\mathrm{SbQ}$ ) com 1750 graus de polimerização (Toyo Gosei Co/Chiba, Japão) e glutaraldeído (Sigma/Amystang, Alemanha), foram estocados sob refrigeração a $4^{\circ} \mathrm{C}$. Obtiveram-se padrões dos pesticidas carbaril e carbofuran (Figura 1) da Sigma, sendo as soluções estoque dos pesticidas preparadas em metanol e estocadas a $-4^{\circ} \mathrm{C}$. Preparam-se soluções de trabalho a partir de diluições das soluções-estoque em água deionizada. Após cada bateria de análises de inibições, essas foram descartadas em reservatório destinado para esse fim. Somente reagentes de grau analítico foram utilizados nas análises.

\subsection{EQUIPAMENTOS}

Efetuou-se a investigação da atividade enzimática e a determinação das constantes de inibição em espectrofotômetro ultravioleta/visível (Ultrospect 4000, Biotech Pharmacia). Foram utilizadas microcubetas de poliestireno descartáveis (Alemanha), micropipetas automáticas de volumes variados (Gilson), lâmpada de neônio para a etapa de fotopolimerização a frio e analisador voltamétrico BAS CV50W (Gateway) para as avaliações eletroquímicas.

\section{FIGURA 1 - ESTRUTURA MOLECULAR DOS PESTICIDAS CARBAMATOS ESTUDADOS}
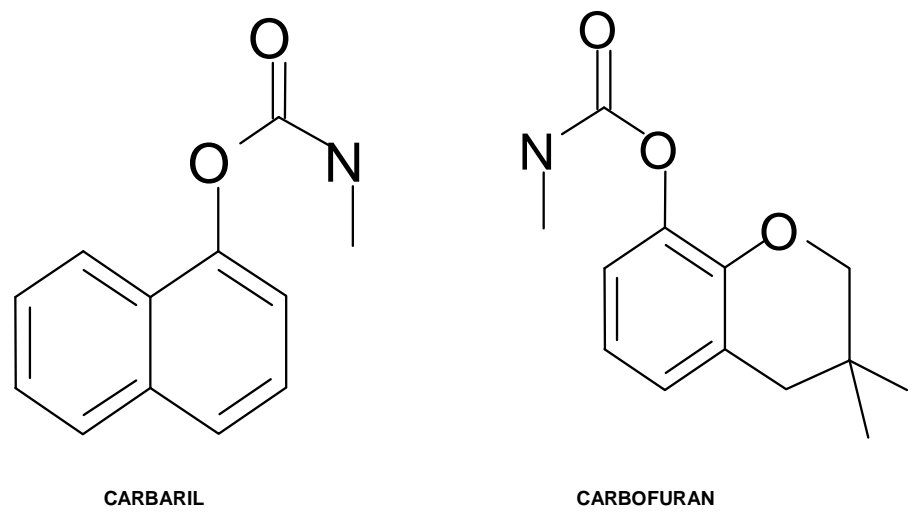

\subsection{PREPARO DO SENSOR IMPRESSO}

Para os ensaios eletroquímicos foram utilizados sensores do tipo screen printed planos descartáveis, impressos em suporte de PVC (cedidos pelo professor Jean Louis Marty Perpignan, França), formados de dois eletrodos impressos em cinco camadas sobrepostas (Figura 2).

Após a impressão do eletrodo de trabalho, os sensores foram acondicionados sob refrigeração $(4 \stackrel{\circ}{ }$ ) por cinco dias. Depois de transcorrido esse tempo, o conjunto eletródico estava pronto para a modificação efetuada sobre o eletrodo de trabalho com a pasta contendo a enzima (NUNES et al., 2001). 


\section{FIGURA 2 - SEQÜÊNCIA DE APLICAÇÃO DAS CAMADAS PARA FABRICAÇÃO DOS ELETRODOS DE DOIS CANAIS PELA TÉCNICA DE SERIGRAFIA}

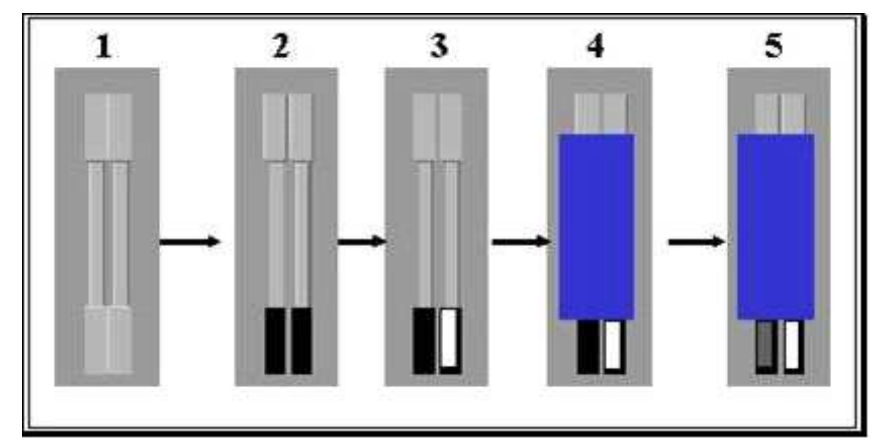

1 Camada de contato elétrico: linhas de conexões de condução de prata (Electrodag PF410, Acheson), que formam o caminho elétrico;

2 Camada de carbono: constituída de pasta de grafite (Electrodag 423SS, Acheson). Evita o contato entre o caminho-prata e o analito, auxiliando na fixação do mediador e da enzima;

3 Eletrodo de referência: pasta de $\mathrm{Ag} / \mathrm{AgCl}$ (Electrodag 603SS, Acheson), impressa sobre a camada de grafite; Camada isolante: tinta epóxi brilhante, evitando contato com a solução;

5 Eletrodo de trabalho: constituído de pasta de grafite T15 (Lonza), contendo a mistura tetracianoquinodimetano (TCNQ) e hidroxietilcelulose (HEC), impressa sobre a camada de carbono restante.

\subsection{DETERMINAÇÃO DAATIVIDADE E CONSTANTES DE INIBIÇÃO ENZIMÁTICAS}

Empregou-se a metodologia cinética de ELLMAN modificada (NUNES et al., 2001; ELLMAN et al., 1961). A hidrólise do substrato (ATChCl), catalisada pela enzima, produziu a tiocolina (TCh) que reagiu posteriormente com o ácido 5,5'-ditiobis(2-nitrobenzoico) [DTNB], ocasionando a formação de complexo amarelo que absorve em $412 \mathrm{~nm}$. Monitorou-se a reação pela medida da absorbância em função do tempo, seguindo a lei de Beer para crescentes concentrações do produto formado.

Para o cálculo da atividade enzimática, a velocidade da reação foi definida pela inclinação na porção linear do gráfico (Abs $x$ tempo). Pipetou-se a solução de trabalho da enzima para a cubeta, sendo adicionados os reagentes tampão fosfato, DTNB e, por último o substrato. Monitorou-se a reação pelas leituras de absorbância conforme o tempo. Foram efetuados 3 ensaios, sendo 1 branco (ausência total de enzima e substrato), um testemunho (ausência de enzima e presença de substrato) e a reação completa (enzima e o substrato). Para a avaliação da constante de inibição dos pesticidas, o meio reacional continha diferentes concentrações do inibidor. Soluções de pesticidas inibidores foram preparadas por diluições da solução estoque $\left(10^{-2} \mathrm{~m} \mathrm{~L}^{-1}\right)$. Foram adicionados à cubeta: $200 \mu \mathrm{L}$ de solução $2,5 \mathrm{~mm} \mathrm{~L}^{-1}$ de DTNB em $350 \mu \mathrm{L}$ de tampão fosfato e $50 \mu \mathrm{L}$ da mistura, contendo $2 \mu \mathrm{L}$ de solução inibidora e $10 \mu \mathrm{L}$ de solução AchE, mais $200 \mu \mathrm{L}$ de substrato. As curvas espectrofotométricas (absorbância $x$ tempo) foram obtidas durante 1 min e a inclinação da curva tomada a cada 3 min, durante $30 \mathrm{~min}$ de incubação com o pesticida. Efetuaram-se ensaios sem o pesticida e ensaios em branco (sem a mistura enzima-inibidor). Com esse procedimento foram determinadas as constantes de Michaelis-Menten, na ausência $\left(\mathrm{K}_{\mathrm{M}}\right)$ e na presença dos inibidores $\left(\mathrm{K}_{\text {Mobs }}\right)$.

\subsection{IMOBILIZAÇÃO DAS ENZIMAS}

O processo de imobilização constitui etapa fundamental na construção de qualquer biossensor. NUNES, JEANTI e MARTY (2004) avaliaram vários procedimentos de imobilização em eletrodos impressos por cronoamperometria e coulometria, destacando a importância dessa etapa para obter melhor desempenho de sensores descartáveis. No presente trabalho foram testados dois métodos de imobilização: i) fotopolimerização da enzima com PVA-SbQ, sob luz de neônio, e ii) ligação cruzada com glutaraldeído. No primeiro método, a solução de imobilização continha tampão fosfato, enzima (concentração previamente estabelecida) e PVA-SbQ na proporção de 30\% (v/v). Após homogeinização 
foram aplicados $2 \mu \mathrm{L}$ da mistura na região do eletrodo de trabalho do biossensor. Em seguida, o sensor foi submetido à irradiação sob luz de neônio $(15 \mathrm{~W})$ por $3 \mathrm{~h}$ sob refrigeração $\left(4^{\circ} \mathrm{C}\right)$ para facilitar a polimerização. Deixou-se o compósito em refrigeração $\left(4^{\circ} \mathrm{C}\right)$ por $20 \mathrm{~h}$. Os biossensores assim preparados foram armazenados em depósitos de plástico, vedados com parafilm e protegidos da luz (prontos para uso). No segundo método de imobilização, a solução continha tampão fosfato, enzima (concentração previamente estabelecida) e glutaraldeído na proporção de 15\% (v/v). Após homogeinização, $2 \mu \mathrm{L}$ da mistura foram aplicados no eletrodo de trabalho. $\mathrm{O}$ biossensor foi deixado sob refrigeração $\left(4^{\circ} \mathrm{C}\right)$ durante $24 \mathrm{~h}$ e armazenado conforme já descrito.

\subsection{CARACTERIZAÇÃO ELETROQUÍMICA DO SISTEMA}

Após o preparo do sensor, iniciou-se a caracterização eletroquímica do sistema sensor-enzima imobilizada. Inseriu-se o biossensor em conector apropriado, que tornou possível o contato entre o potenciotasto (detector) e o sensor. Mediu-se a intensidade da corrente mediante imersão do biossensor em solução contendo o tampão e o substrato de concentrações conhecidas. Inicialmente, o sinal relativo ao tampão foi cronoamperometricamente registrado, sendo estabelecido como "linha de base". O sinal de corrente relativo à resposta enzimática com o substrato foi posteriormente obtido. Utilizouse potencial fixo (100 mv) e monitorou-se a intensidade de acordo com o tempo (NUNES et al., 2001). O princípio da reação enzimática monitorada foi baseada na hidrólise do substrato enzimático, produzindo tiocolina e ácido acético (reação 1). A tiocolina foi então oxidada no eletrodo de trabalho.

$$
\begin{aligned}
\stackrel{\text { ATCh }}{+\mathrm{H}_{2} \mathrm{O}} \stackrel{\text { AChE}}{\longrightarrow} \mathrm{TCh}+\mathrm{HA} \\
\text { acetiltiocolina } \\
\text { tiocolina ácido acético } \\
2 \mathrm{TCh}_{\text {red }} \longrightarrow \mathrm{TCh}_{\text {oxi }}+2 \mathrm{H}^{+}+2 \mathrm{e}-
\end{aligned}
$$

A corrente elétrica gerada durante o processo foi monitorada como atividade da enzima. Foram efetuados, assim, ensaios de repetitividade de sinal, melhor concentração de substrato, otimização da carga enzimática e reprodutibilidade/repetitividade dos procedimentos de imobilização.

\subsection{ESTUDO DE INIBIÇÃO}

As curvas analíticas dos pesticidas carbaril e carbofuran foram constituídas com base no princípio de inibição da colinesterase. Obteve-se o sinal inicial pela imersão do biossensor em solução de substrato, seguido de corrida cronoamperométrica em potencial fixo de $100 \mathrm{mv}$, registrando-se então a intensidade de corrente $\left(\mathrm{S}_{0}\right)$. Em seguida, o sensor foi lavado com água deionizada, enxugado com papel ultramacio e mergulhado na solução do inibidor. Depois de transcorrido o tempo necessário para a inibição (incubação), o sensor foi novamente lavado com água, enxugado, mergulhado na solução de substrato, e registrada nova corrida cronoamperométrica (sob as mesmas condições), sendo medido o novo sinal após inibição $\left(S_{1}\right)$. A inibição relativa $(\% / R)$ da enzima foi verificada por decréscimo da corrente estacionária, sendo calculada segundo SKLÁDAL, PAVLIK e FIALA (1994). Os ensaios de inibição foram repetidos com diferentes concentrações dos inibidores.

\subsection{ENSAIOS DE RECUPERAÇÃO}

Amostras de água de abastecimento foram coletadas diretamente da torneira dos laboratórios de pesquisa em química (UFMA), segundo normas específicas de amostragem (AGUDO, 1987). Preparou-se a solução fortificada adicionando $500 \mu \mathrm{L}$ de tampão fosfato em $1000 \mu \mathrm{L}$ de amostra (em 
tubos eppendorf) e $500 \mu \mathrm{L}$ de solução de pesticida, totalizando $2000 \mu \mathrm{L}$ de solução do pesticida com concentração final conhecida. Imergiu-se o sensor em amostras fortificadas com concentrações conhecidas dos inibidores, sendo o percentual de inibição calculado e "plotado" diretamente nas curvas analíticas para determinar as recuperações.

\section{RESULTADOS}

\subsection{INVESTIGAÇÃO DAS ATIVIDADES E CONSTANTES DE INIBIÇÃO ENZIMÁTICAS}

As atividades das enzimas nas soluções $(\mathrm{U} / \mathrm{mL})$ foram determinadas, antes de se efetuar cada imobilização. Realizou-se estimativa da constante de inibição $\left(\mathrm{K}_{\mathrm{i}}\right)$ mediante variadas concentrações dos pesticidas. Depois de tomada a curva cinética para cada concentração nos tempos de incubação, os valores das inclinações encontrados foram utilizados para os cálculos da atividade residual (AR). $O$ logaritmo da atividade residual foi plotado em relação ao tempo de análise (em minutos). A Figura 3 apresenta a curva de decréscimo do logaritmo da atividade residual da AChE (ee), após a incubação com o carbaril, em diferentes concentrações e em crescentes tempos de incubação.

\section{FIGURA 3 - DECRÉSCIMO DA ATIVIDADE RESIDUAL DA ENZIMA ACETILCOLINESTERASE (EE), DURANTE INCUBAÇÃO COM DIFERENTES CONCENTRAÇÕES DO INIBIDOR CARBARIL, EM TEMPO CRESCENTE (EE = ENGUIA ELÉTRICA)}

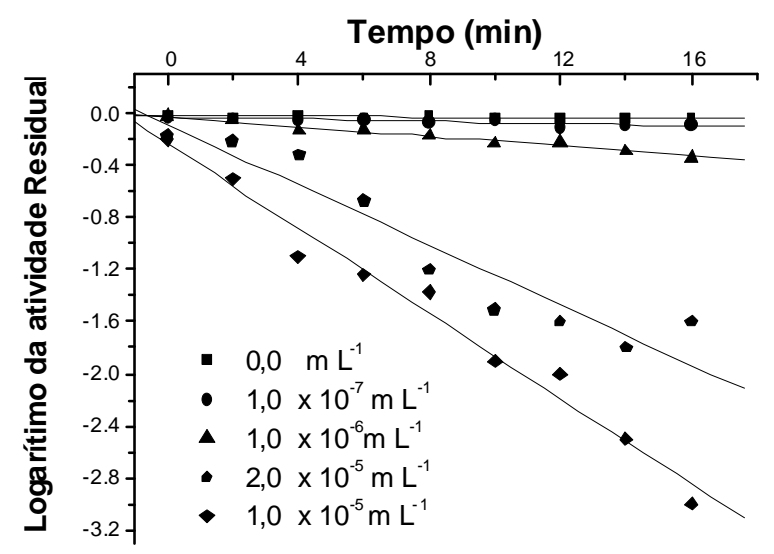

A partir da regressão linear das curvas (Figura 3) foram obtidos os valores das inclinações de cada curva, que equivalem às constantes de Michaelis-Menten observadas após inibição enzimática $\left(\mathrm{K}_{\text {Mobs }}\right)$. Foram traçados, então, gráficos de correlação entre as diferentes concentrações do inibidor e as constantes de Michaelis-Menten (Figura 4).

O inverso da inclinação da reta (Figura 4) forneceu o valor da constante de inibição. Para o carbaril, essa constante foi $\mathrm{K}_{\mathrm{i}}=5 \times 10^{4} \mathrm{~mol}^{1} \mathrm{~L}$ min ${ }^{1}$ e para o carbofuran $\mathrm{K}_{\mathrm{i}}=1 \times 10^{7} \mathrm{~mol}^{1} \mathrm{~L}$ min ${ }^{1}$. Esses dados indicaram que o carbofuran é um inibidor de colinesterases muito mais forte do que 0 carbaril, apesar das classificações como inseticidas serem semelhantes (TOMLIN, 1994). Os valores de sensibilidade fornecem dados auxiliares para os trabalhos iniciais de construção de biossensores a base de enzimas colinesterases para a detecção de carbamatos. NUNES, JEANTY e MARTY (2004) avaliaram as constantes de inibição enzimática para o inseticida organofosforado metamidofós (inibidor de colinesterase), sendo encontrados valores de $\mathrm{k}_{\mathrm{i}}$ variando de $1 \times 10^{3} \mathrm{a} 1 \times 10^{6} \mathrm{~mol}^{1} \mathrm{~L} \mathrm{~min}{ }^{1}$ para enzimas oriundas de Drosophila melanogaster. Comparado com esses estudos, o carbofuran apresenta grau de inibição mais forte ainda que o pesticida organofosforado, ratificando a importância da pesquisa com detecção rápida de carbamatos em matrizes aquáticas. 


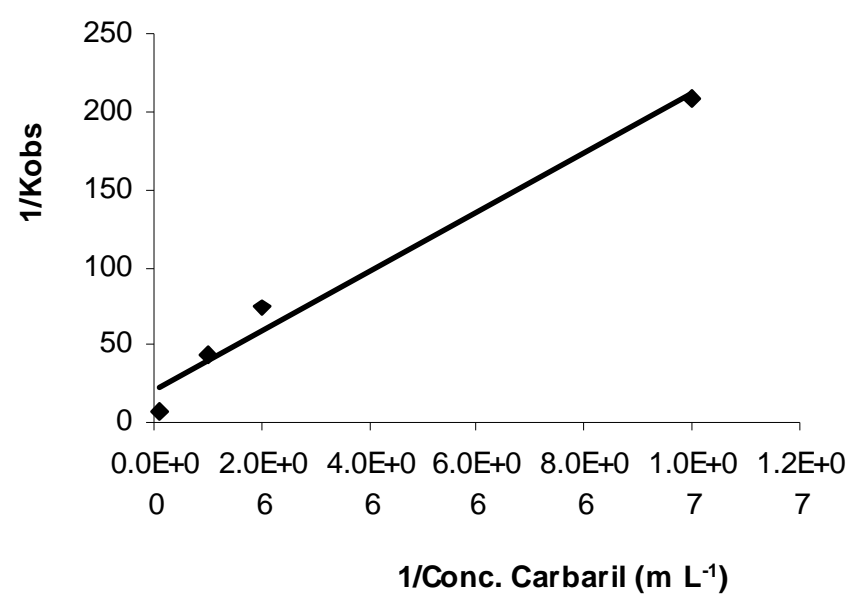

3.2 IMOBILIZAÇÃO DAS ENZIMAS

O método de imobilização com glutaraldeido não necessitou do aparato da luz de neônio, aumentando a rapidez do processo. Além disso, o procedimento pode ser conduzido em temperatura ambiente, o que não foi observado para o método do PVA-SbQ. Os sensores obtidos apresentaram boa estabilidade, não havendo perdas de camada enzimática, durante as medidas eletroquímicas efetuadas sempre sob agitação.

\subsection{OTIMIZAÇÃO DE PARÂMETROS OPERACIONAIS}

Foram selecionados os tempos de 3 e 5 min para avaliar a estabilidade do sinal da corrente perante variadas medidas frente ao tampão e ao substrato. As soluções foram substituídas a cada medida e o biossensor lavado com água deionizada. O tempo de $5 \mathrm{~min}$ apresentou melhor repetitividade de corrente, sendo selecionado para ensaios posteriores (Figura 5). O coeficiente de variação obtido para as medidas efetuadas nesse tempo ficou em torno de $6,8 \%$.

\section{FIGURA 5 - COMPARAÇÃO ENTRE A REPETITIVIDADE DE CORRENTE NOS TEMPOS DE 3 E 5 MINUTOS}

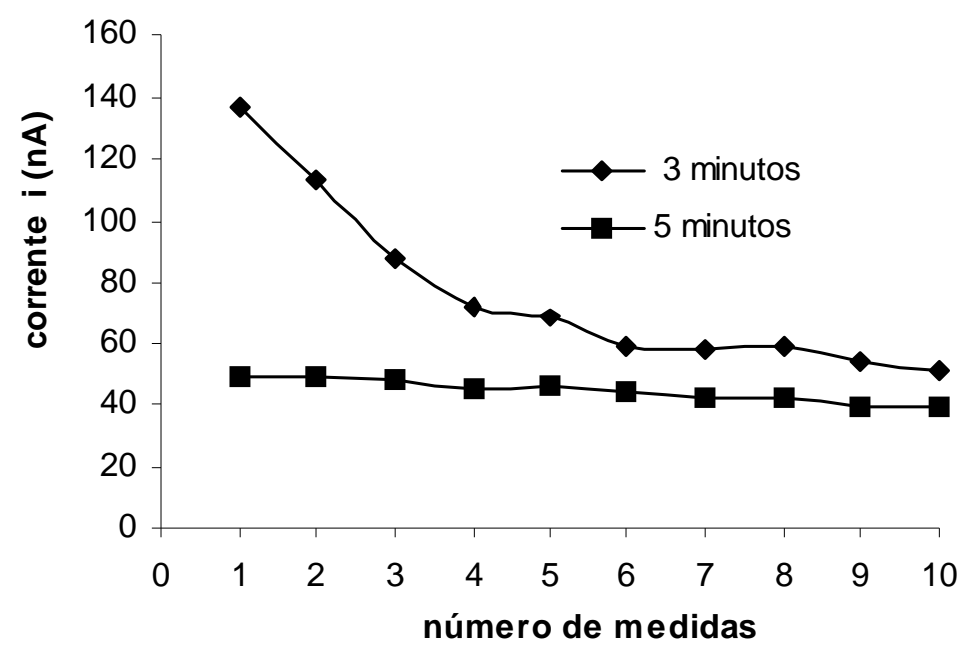

Condições Operacionais: potencial de $100 \mathrm{Mv},[\mathrm{ATCHCL}]=1 \mathrm{~mm} \mathrm{~L}^{-1}$ versus $\mathrm{ACHE}(\mathrm{EE})$. 


\subsection{OTIMIZAÇÃO DA QUANTIDADE DE ENZIMA E SELEÇÃO DO MÉTODO DE IMOBILIZAÇÃO}

Para melhor evidência do decréscimo de corrente nos ensaios posteriores de inibição, a quantidade de enzima a ser imobilizada deveria apresentar sinal de corrente perante o substrato $\left(1 \mathrm{~mm} \mathrm{~L}^{-1}\right)$ em torno de $100 \mathrm{nA}$. Nessa fase do trabalho foram testadas as concentrações de $1 \times 10^{-3}$, $1 \times 10^{-2}$ e $1 \mathrm{U} /$ eletrodo. O sinal de corrente foi tomado com o tampão e o substrato. A Figura 6 apresenta a comparação dos dois métodos de imobilização propostos em função da carga enzimática. Optou-se por utilizar $1 \mathrm{U} /$ eletrodo (versus $1 \mathrm{~mm} \mathrm{~L}^{-1}$ de substrato) como carga-padrão para otimização do biossensor, obtendo-se variação significativa de corrente entre o tampão ( $i=4,8 \mathrm{nA}$ ) e o substrato $(i=115 \mathrm{nA})$. O método de imobilização com PVA-SbQ foi selecionado para o processo de imobilização, visto que o mesmo forneceu valores de corrente superiores ao método com glutaraldeído. O glutaraldeído desativa parcialmente a colinesterase no momento da preparação da pasta enzimática, resultando em expressiva diminuição da atividade da enzima (CHIBATA, 1978). Na prática, tem-se observado que esse efeito não é tão expressivo quando se utiliza o PVA-SbQ como agente imobilizador.

\section{FIGURA 6 - AVALIAÇÃO DA CARGA ENZIMÁTICA UTILIZANDO-SE DOIS MÉTODOS DE IMOBILIZAÇÃO}

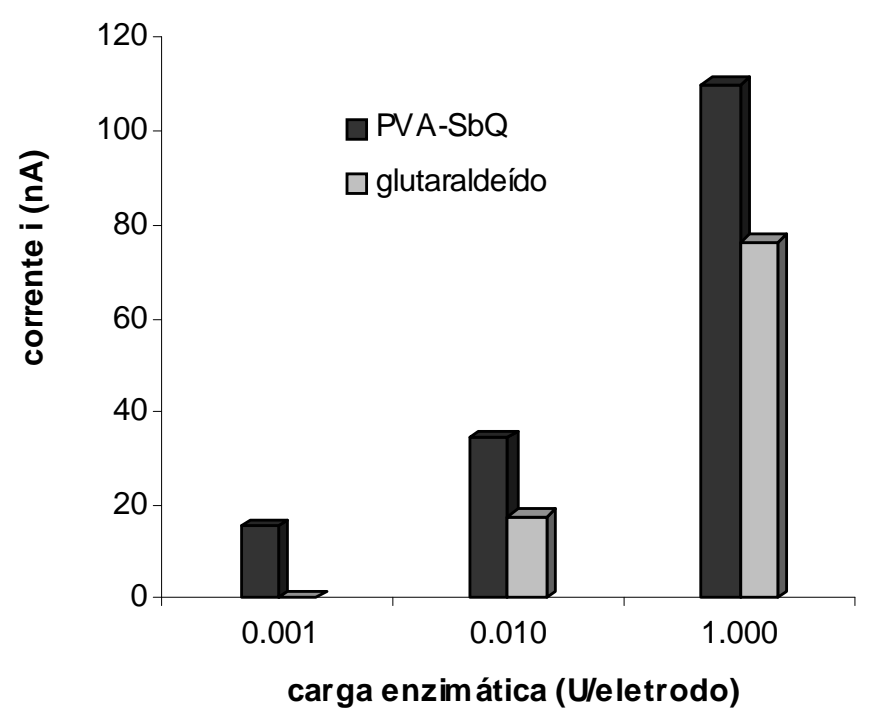

Após a otimização dos parâmetros, o teste de precisão apresentou boa repetitividade com corrente de 103,5 nA \pm 5,5\% e coeficiente de variação de 5,4\%. Desvio-padrão de 7,9\% em torno da média (104,3 nA) foi observado com seis diferentes sensores, preparados por imobilização com PVA$\mathrm{SbQ}$, com coeficiente de variação de $7,6 \%$. Avaliou-se a reprodutibilidade da imobilização com PVA$\mathrm{SbQ}$ usando seis eletrodos diferentes, cujas imobilizações foram efetuadas em dias distintos (intervalo de um mês). Obteve-se média de 99,4 $\pm 18,7 \mathrm{nA}$ com coeficiente de variação de 18,8\%. Esses dados confirmam a reprodutibilidade do processo de imobilização otimizado, mesmo em grandes intervalos de tempo, visto que desvios-padrões abaixo de $20 \%$ têm sido considerados aceitáveis em testes de validação de metodologias. Os coeficientes de variação também se apresentaram abaixo de $20 \%$, sendo mais representativos que o desvio-padrão para avaliação de reprodutibilidade de dados, pois implicam diretamente na precisão do método (WOOD, 1999; BRITO et al., 2003).

\subsection{TESTES DE INIBIÇÃO}

Todos os pontos das curvas analíticas foram avaliados em triplicata, obtendo-se desvios abaixo de $10 \%$. Os ensaios de inibição foram efetuados com tempo de 10 min de incubação e concentrações 
do inibidor entre $0,9 \times 11^{-8}$ e $50 \times 10^{-8} \mathrm{~m} \mathrm{~L}^{-1}$ (Figura 7). Concentrações elevadas de inibidor podem ter afetado os sítios ativos da enzima (tornando-os parcialmente inativos, ou saturando esses sítios), motivo pelo qual a resposta foi praticamente a mesma e acima do valor máximo.

\section{FIGURA 7 - CURVA ANALÍTICA PARA O PESTICIDA CARBARIL}

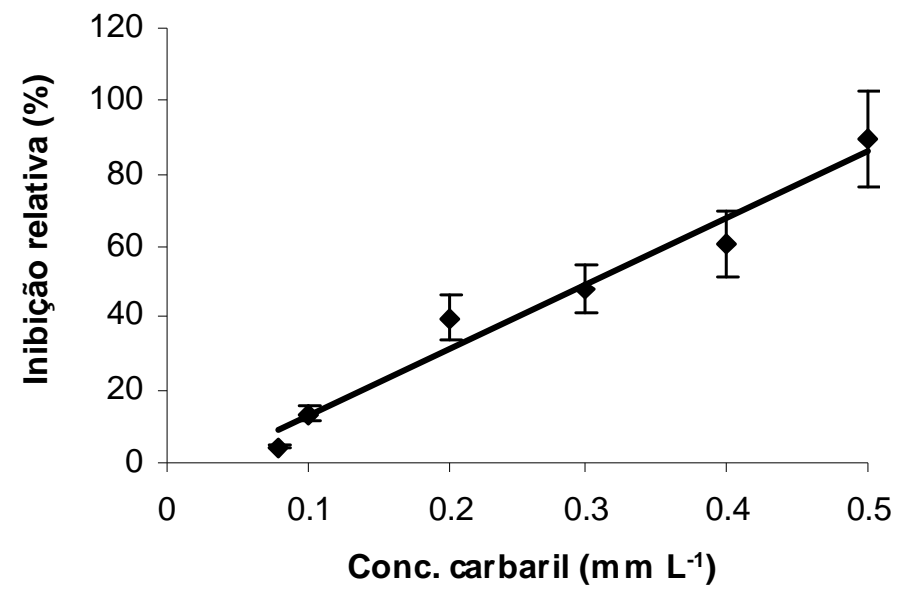

ACHE (ee) $1 \mathrm{U} /$ eletrodo; $\mathrm{ATCHCL}=1 \mathrm{~mm} \mathrm{~L}{ }^{-1}$; potencial de trabalho $=100 \mathrm{mV} ; \mathrm{pH} 7,5$.

A região linear de trabalho apresentada pelo pesticida carbaril foi estreita, porém com limite de detecção de $0,09 \mu \mathrm{mol} \mathrm{L}^{-1}\left(18 \mu \mathrm{g} \mathrm{L}^{-1}\right)$. A legislação brasileira vigente considera o carbaril como substância química de risco para a saúde, mas não especifica valores de concentração que possam ser monitorados. Apenas estabelece que para avaliar a presença de carbamatos em água deve-se determinar a atividade anticolinesterase em torno de $15 \%$ de inibição com ensaio de enzima (BRASIL, 2004). A metodologia apresentada fixa como limite de detecção a faixa mínima de $10 \%$ de inibição, sendo apropriada para monitoramento desse inibidor de colinesterase em água.

\subsection{CARBOFURAN}

O estudo de inibição com o pesticida carbofuran ocorreu de modo semelhante ao do carbaril. Optou-se por trabalhar com concentrações abaixo das usadas para o carbaril em função da elevada toxicidade do carbofuran, comprovada anteriormente pelos ensaios cinéticos. A curva analítica para esse composto (Figura 8) evidenciou comportamento logarítmico, com $R^{2}=0,978$ e limite de detecção em torno de $0,05 \mu \mathrm{g} \mathrm{L}^{-1}$. NUNES et al. (1999) detectaram carbofuran utilizando biossensor em pasta de carbono como eletrodo de trabalho, modificado com ftalocianina de cobalto (CoPC) como mediador eletroquímico. Encontraram limite de detecção de 0,5 e $75 \mu \mathrm{g} \mathrm{L}^{-1}$ para enzimas AChE oriundas de enguia elétrica e eritrócito bovino, respectivamente.

O limite apresentado pelo método em estudo ficou abaixo do exigido pela legislação brasileira (15\% de inibição em colinesterase), podendo ser utilizado para controle e monitoramento desse carbamato em níveis muito baixos de concentração (BRASIL, 2004). O carbofuran é muito mais nocivo às enzimas $\mathrm{AChE}$, necessitando de rápida confirmação e detecção em matrizes aquáticas.

\subsection{ENSAIOS DE RECUPERAÇÃO}

Foram efetuados três ensaios em triplicata para três níveis de fortificação (baixo, médio e alto), escolhidos com base na curva de calibração (concentração pesticida versus inibição relativa). A Tabela 1 apresenta os resultados obtidos para os ensaios com os pesticidas selecionados. 


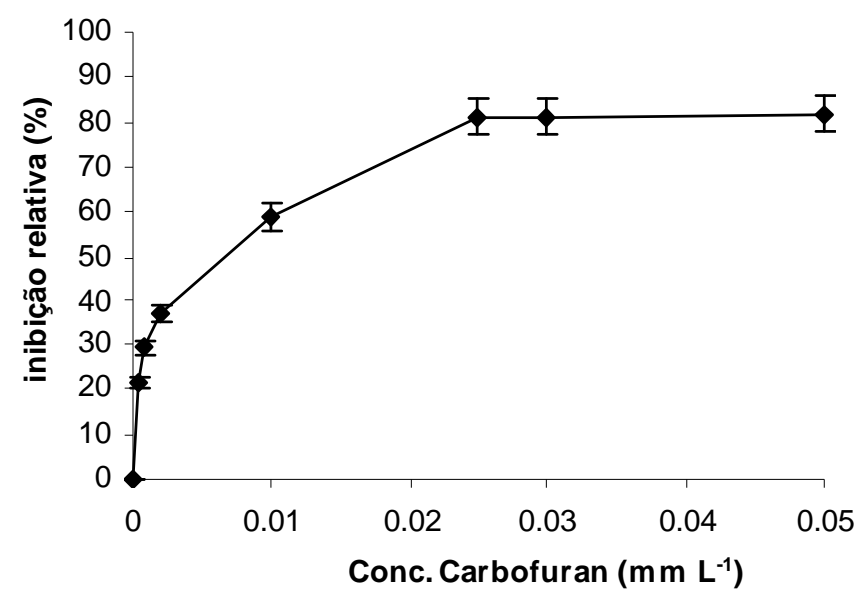

$\mathrm{AChE}(\mathrm{ee}), 1 \mathrm{U} /$ eletrodo; $\mathrm{ATChCl}=1 \mathrm{~mm} \mathrm{~L}{ }^{-1}$; potencial de trabalho $=100 \mathrm{mV} ; \mathrm{pH} 7,5$.

\section{TABELA 1 - RECUPERAÇÕES E COEFICIENTES DE VARIAÇÃO DOS COMPOSTOS DETECTADOS PELO BIOSSENSOR AMPEROMÉTRICO}

\begin{tabular}{c|c|c|c|c}
\hline Pesticida & $\begin{array}{c}\text { Nível de } \\
\text { fortificação }\end{array}$ & Concentração $\left(\mu \mathbf{g ~ L}^{-1}\right)$ & Recuperação* $(\%)$ & CV\%** \\
\hline \multirow{3}{*}{ Carbaril } & 1 & 30 & 118 & 11,6 \\
& 2 & 60 & 92 & 1,2 \\
& 3 & 100 & 98 & 9,1 \\
\hline \multirow{3}{*}{ Carbofuran } & 1 & 1,3 & 88 & 5,3 \\
& 2 & 6,6 & 91 & 7,1 \\
& 3 & 12,0 & 101 & 7,0 \\
\hline
\end{tabular}

${ }^{*}$ Média de três replicatas. ${ }^{*} \mathrm{CV}=$ coeficiente de variação(\%).

Para o carbaril, a média das recuperações ficou em $102,7 \pm 13,6 \%$ e CV de 13,3\%. Para o carbofuran, a média foi de $93,3 \pm 6,8 \%$ e CV de $7,3 \%$. A média geral de recuperação em torno de $98 \pm$ $11 \%$, com CV de 11,1\%, demonstra excelente precisão do método otimizado. Para esses níveis de concentrações, recuperações com até $20 \%$ de CV são aceitáveis (BRITO et al., 2003). SUWANSAARD et al. (2005) obtiveram recuperações médias de $91 \pm 9 \%$ para o carbaril em amostras de água filtradas, sem pré-tratamento, utilizando biossensores potenciométricos e análise por injeção em fluxo. Os valores de recuperação apresentados demonstram ótima exatidão do biossensor impresso, construído a base de enzimas colinesterases para determinação dos pesticidas selecionados em matrizes aquáticas.

\section{CONCLUSÃO}

Este estudo apresentou uma proposta para detecção de carbamatos em água de abastecimento, empregando metodologia de screening. O método de imobilização da enzima baseado em fotopolimerização com PVA-SbQ foi selecionado para a construção do biossensor, devido ao maior sinal de corrente cronoamperométrica em comparação com o método do glutaraldeido. As curvas analíticas apresentaram limites de detecção abaixo dos limites máximos recomendados (LMR) pelos 
organismos nacionais de controle. O carbofuran apresentou maior constante de inibição que o carbaril, o que foi evidenciado posteriormente pelo maior grau de inibição da enzima imobilizada. Os ensaios de recuperação mostraram elevada exatidão para o método de detecção de pesticidas carbamatos em água com os biossensores a base de AChE, atendendo às exigências analíticas para a direta aplicação de sensores descartáveis em amostras reais.

\section{ABSTRACT}

\section{AMPEROMETRIC BIOSENSOR TO DETECT SCREENING OF CARBAMATE INSECTICIDES IN DRINKING WATER}

Amperometric biosensor based on cholinesterases enzymes (AChE) immobilized in screen-printing electrode, was used to detect carbamates pesticides (carbofuran and carbaryl) in drinking water samples. Initially, inhibition constants for the insecticides carbaryl $\left(1 \times 10^{7}\right)$ and carbofuran $\left(5 \times 10^{4}\right)$ were studied. A two-channel screen-printed strip containing a TCNQ-graphite-modified and a $\mathrm{Ag} / \mathrm{AgCl}$ electrode as working and reference electrodes, were used respectively. Two enzyme immobilization procedures were evaluated aiming the optimization of the biosensor. The methodologies of photopolimerization with poly(vinyl alcohol), bearing styrylpyridinium groups (PVA-SbQ) and crosslinking with glutaraldehyde were selected for the study. The PVA-SbQ agent has shown better results $(\mathrm{CV}=6.5 \%)$. Analytical curves were plotted after inhibition assays with the pesticides and the limits of detection (LOD) were determined. Carbaryl gives a linear curve (LOD of $18 \mu \mathrm{g} \mathrm{L}^{-1}$ ), while carbofuran provides a logarithmic curve (LOD of $0,05 \mu \mathrm{g} \mathrm{L}^{-1}$ ). The accuracy of direct pesticide detection with the optimized biosensor was also evaluated. Three spiking levels were studied and average recoveries varied from $93.3 \%$ to $102.7 \%$. The AChE-based biosensor assisted analytical demands for the direct application of sensor disposable in real samples.

KEY-WORDS: AMPEROMETRIC BIOSENSORS; CARBAMATES; DRINKING WATER; CARBARYL; CARBOFURAN.

\section{REFERÊNCIAS}

1 AGUDO, E. G. Guia de coleta e preservação de amostras de água. São Paulo: CETESB, 1987. 150 p.

2 ALBAREDA-SIRVENT, M.; MERKOÇI, A.; ALEGRET, S. Configuration in the design of screen-printed enzymatic biosensors. A review. Sen. and Actuators B, v. 69, p.153-163, Set.2000.

3 BARCELÓ, D. Environmental Protection Agency and other methods for the determination of pesticides and their transformation products in water. J. Chromatogr. A., v. 643, n.1-2, p. 117-143, Jul.1993.

4 BASSI, A.S.; TANG, D.; LEE, E.; ZHU, J.X.; BERGOUGNOU, M. A. Biosensors in environmental and bioprocess monitoring and control. Food Technol. Biotechnol., v. 34, n. 1, p. 9-22, Jan.1996.

$5 \mathrm{BICCHI,C.;} \mathrm{DAMATO,} \mathrm{A.;} \mathrm{BALBO,} \mathrm{C.} \mathrm{Multiresidues} \mathrm{for} \mathrm{the} \mathrm{quantitative} \mathrm{gas} \mathrm{chromatographic} \mathrm{determination} \mathrm{of} \mathrm{pesticides}$ residues in sweet cherries. J. AOAC. Inter., v. 80, n. 6, p. 1281-1286, Jun.1997.

6 BOTKLIN, D. B.; KELLER, E. A. Environmental science: Earth as a living planet. $3^{\text {rd }}$ ed. New York: WILEY, 2000.

7 BRASIL. Ministério da Saúde. Portaria № 518 de 25 de março de 2004. Estabelece os procedimentos e responsabilidades relativas ao controle e vigilância de qualidade da água de consumo humano e seu padrão de potabilidade, e dá outras providências. Diário Oficial [da] República Federativa do Brasil, Brasília, 26 de março de 2004, seção 1, p. 266.

8 BRITO, N. M.; AMARANTE JUNIOR, O. P.; POLESE, L.; RIBEIRO, M. Validação de métodos analíticos: estratégia e discussão. Pesticidas: revista de ecotoxicologia e meio ambiente, Curitiba, v. 13, p.129-146, jan./dez.2003.

9 CHEMNITIUS, G.; MEUSEL, M.; ZABOROSCH, C.; KNOLL, M.; SPENER, F.; CAMMANN, K. Highly sensitive electrochemical biosensors for water monitoring. Food Technol. Biotechnol., v. 34, n. 1, p. 23-29, Jan.1996.

10 CHIBATA, I. Immobilized enzyme: research and development. New York: John Wiley, 1978.

11 ELLMAN, G.L.; COURTNEY, K.P.; ANDRES, V.; FEARSTHERSTONE, R.M. A new and rapid colorimetric determination of acetylcholinesterase activity. Biochem. Pharmacol, v. 7, n. 2, p. 88-90, Jul.1961.

12 FAtiBello FILHO, O.; CAPELATO, M. D. Biossensores. Quím. Nova, São Paulo, v. 15, n. 1, p. 28-39, jan/fev.1992.

13 HASSAL, K. A. The biochemistry and use of pesticides: structure, metabolism, mode action and uses in crop protection. $2^{\text {nd }}$ ed. New York: Weihein, 1990. 536 p. 
15 LEHOTAY, S. J. Development of a sample preparation technique for supercritical fluid extraction for multiresidues analysis of pesticides in produce. J. AOAC Inter., v. 78, n. 3, p. 831-840, May/Jun.1995.

16 LI, H. P.; LI, J. H.; LI, C. L.; JEN, J. F. Simultaneous determination of airborne carbamates in workplace by high performance liquid chromatography with fluorescence detection. Talanta, v. 63, n. 3, p. 547-553, Jun.2004.

17 MARQUES, P. R. B. O.; NUNES, G. S.; SANTOS, T. C. R.; ANDREESCU, S.; MARTY, J.L. Comparative investigation between acetylcholinesterase obtained from commercial sources and genetically modified Drosophila melanogaster: application in amperometric biosensors for methamidophos pesticide detection. Biosens. Bioelectron., v. 20, n. 4, p. 825-832, Nov.2004.

18 MARTY, J. L.; GARCIA, D.; ROUILLON, R. Biosensors: potential in pesticides detection. Trends. Anal. Chem., v. 14, n. 7, p. 329-333, Aug.1995.

19 NUNES, G. S. Determinação de pesticides utilizando biossensores a base de enzimas colinesterases: uma revisão. Pesticidas: revista de ecotoxicologia e meio ambiente, Curitiba, v. 6, p. 13-30, jan/dez.1996.

20 NUNES, G. S.; JEANTY, G.; MARTY, J. L. Enzyme immobilization procedures on screen-printed electrodes used for the detection of anticholinesterase pesticides: comparative study. Anal. Chim. Acta, v. 523, n.1, p. 107-115, Oct.2004.

21 NUNES, G.S.; MONTESINOS, T.; MARQUES, P.B.O.; FOURNIER, D.; MARTY, J. L. Acetylcholine enzyme sensor for determining methamidophos insecticide: evaluation of some genetically modified acetylcholinesterases from Drosophila melanogaster Anal. Chim. Acta, v. 434, n. 1, p. 1-8, Apr.2001.

22 NUNES, G. S.; RIBEIRO, M. L. Pesticidas: uso, legislação e controle. Pesticidas: revista de ecotoxicologia e meio ambiente, Curitiba, v. 9, p. 31-44, jan./dez.1999

23 NUNES, G. S.; SKLÁDAL, P.; YAMANAKA, H.; BARCELÓ, D. Determination of carbamate residues in crop samples by cholinesterase-based biosensors and chromatographic techniques. Anal. Chim. Acta, v. 362, n.1, p. 59-68, Apr.1998.

24 O'NEIL, P. Environmental chemistry. 2 ${ }^{\text {nd }}$ ed London: Chapman \& Hall, 1993. 233 p.

25 SALAU, J. S. et al. Application of solid-phase disk extraction followed by gas and liquid chromatography for the simultaneous determination of the fungicides: captan, captafol, carbendazim, chlorothalonil, ethirimol, folpet, metalaxyl and vinclozolin in environmental waters. Anal. Chim. Acta, v. 293, n. 1-2, p. 109-117, Jul.1994.

26 SCHELLER, F.; SCHMID, R. D. (Ed). Biosensors: fundamentals, technologies and application. Berlin: CHV, 1991. v. 17.

27 SCHEPER, T. H.; HILMER, J. M.; LAMMERS, F.; MÜLLER, C.; REINECKE, M. Biosensors in bioprocess monitoring. J. Chromatogr. A, v. 725, n.1, p. 3-12, Fev.1996.

28 SKLÁDAL, P. Determination of organophosphate and carbamate pesticides using a cobalt phthalocyanine-modified carbon paste electrode and a cholinesterase enzyme membrane. Anal. Chim. Acta, v. 252, n.1-2, p. 11-15, Nov.1991.

29 SKLÁDAL, P.; PAVLIK, M.; FIALA, M. Pesticides biosensor based on coimobilized acetylcholinesterase and butyrylcholinesteras. Anal. Lett., v. 27, n. 1, p. 29-40, Jan.1994.

30 STANLEY, E. M. Fundamentals of environmental chemistry. $2^{\text {nd }}$ ed. New York: Lewis, 1993.540 p.

31 STEVENS, R. W. (Ed) Pesticides in the environmental. New York: Marcel Dekker, $1997 . v .3$.

32 SUWANSA-ARD, S.; KANATHARANA, P.; ASAWATRERATANAKUL, P.; LIMSAKUL, C.; WONGKITTISUKSA, B.; THAVARUNGKUL, P. Semi disposable reactor biosensors for detecting carbamate pesticides in water. Biosens. Bioelectron., v. 21, n. 3, p 445-454, Set.2005.

33 TOMLIN, C. (Ed.) The pesticide manual: incorporating the agrochemicals handbook. 10 $0^{\text {th }}$ ed. Bath: Royal Chemical Society, 1995. $1150 \mathrm{p}$. WHEELER, W. B. (Ed). Pesticides in agriculture and the environment. New York: Marcel Dekker, 2002.330 p. WOOD, R. How to validate analytical methods. Trends Anal. Chem., v. 18, n. 9-10, p. 624-632, Set.1999.

36 ZHANG, S.; YANG, G. W. Y. Materials and techniques for electrochemical biosensor design and construction. Biosens. Bioelectron., v. 15, n. 5-6, p. 273-282, Aug.2000. 